\title{
Saving One Smile at a Time: Oral Health Promotion in Pediatric Primary Care Practice
}

\author{
Deborah J. Mattheus*, Charl Mattheus \\ University of Florida, Gainesville, USA \\ Email: dmattheus@ufl.edu, charl.mattheus@medicine.ufl.edu
}

Received 30 March 2014; revised 3 May 2014; accepted 15 May 2014

Copyright (C) 2014 by authors and Scientific Research Publishing Inc.

This work is licensed under the Creative Commons Attribution International License (CC BY). http://creativecommons.org/licenses/by/4.0/

c) (i) Open Access

\begin{abstract}
Oral health continues to be a major issue affecting children these days. Early childhood caries are considered to be the most common chronic childhood disease in the United States. Despite the availability of Medicaid, millions of children can still not access a dental provider to receive proper care. Getting children in for dental care early in their lives saves money. Children that do not receive proper oral health care during their childhood are at higher risk for more complex and restorative care as they age. Plans to reduce childhood caries include more creative interventions such as oral assessment, education and fluoride varnish application in primary care practices. Pediatric primary care providers are trusted by parents to care for their children and have an ideal opportunity to make a lasting impression and create behavioral changes in oral health during their frequent contacts with children and families. Integrating oral health promotion is a simple task with numerous benefits for children and families, as well as primary care doctors' offices. With proper professional and governmental support oral health promotion programs in primary care practice can further increase in number which can ultimately improve oral health outcomes, save time and prevent costly dental repairs, as well as benefit the practice through proper reimbursement.
\end{abstract}

\section{Keywords}

Early Childhood Caries, Oral Health Promotion, Primary Care Practice

\section{Introduction}

Oral health is a major public health issue affecting today's children and their families. Dental caries in the Unit-

*Deborah J. Mattheus: PhD, MSN, CPNP. 
ed States are the most common chronic childhood disease, occurring 5 to 8 times more frequently than asthma [1]. The Center for Disease Control and Prevention (CDC) reports that more than one in four (28\%) preschoolers experience tooth decay [2]. Despite acknowledgement of this problem by dental and health providers little has changed to improve these statistics. Recent reports by the Center for Disease Control (CDC) revealed that one in five of all children between 6 and 19 years have untreated dental carries [3].

Dental caries are established as an active disease process before 2 years of age. Therefore, the best opportunity for reducing the risk factors associated with carie formation is during the infant and toddler stages of life [4]-[8]. The AAP recommends that all children have an oral health risk assessment by 6 months, and see a dentist between 6 and 12 months if they are in a high-risk category for dental decay [9]. Unfortunately, multiple barriers currently exist which prevent adequate access to dental care for this young and vulnerable population, making this an unrealistic expectation.

\section{Barriers to Dental Care}

The major limitation to decreasing childhood dental disease includes shortages in pediatric dental services and dental providers who are both willing and able to provide services to uninsured children, as well as those children with Medicaid insurance [10]-[14]. According to a Pew research report in 2011 there were 29 million children enrolled in Medicaid however only 12.9 million received dental care, with the inability to access a provider noted to be the major limiting factor [15]. Current and future dental care trends indicate that there will be a continued lack of access to dental services by the uninsured as well as underprivileged children with Medicaid insurance. Unfortunately, these groups are in greatest need of oral health services.

\section{Consequences of ECC}

A direct relationship has been made between oral health and quality of life [16]. The US Surgeon General's report on oral health identified numerous studies focusing on the negative consequences of poor oral health, including impaired eating, difficulty speaking and adversely impacting the development of self-esteem and social interaction [1]. Poor oral health in children has been shown to decrease school performance as well as affecting social and behavioral development with over 51 million hours lost from school each year due to dental problems [15].

Children experiencing caries as infants or toddlers also have a greater chance of developing caries of primary and permanent teeth later during childhood and adulthood [17]. Poor health outcomes also extend into adulthood with dental disease considered to be a risk factor for multiple health conditions including adult heart disease (e.g., coronary artery disease, myocardial infarction), compromised pregnancy outcomes, and immune, infectious and inflammatory diseases[18] [19].

\section{Economic Burden}

Although oral health is known to affect more than the mouth it appears to be a low priority in the past with many children experiencing pain, eating problem, self-esteem and the possibility of a life threatening infection causes by dental disease. Getting children in for dental care early in their lives saves money. Children that do not receive proper oral health care during their childhood are at higher risk for more complex and restorative care as they age. Children who have their first preventive dental visit by 1 year are noted to have lower dental costs later in their lives [20].

According to Truman, Gooch \& Sulemana [21] cavities are the $4^{\text {th }}$ most expensive disease in the United States. Dental emergencies are also noted to be the second leading cause of outpatient surgeries at children's hospital [22]. The care of a child requiring treatment for a dental infection in the hospital is costly and often the cost of treatment include admission, antibiotics, and nursing services easily reaching above $\$ 10,000$. In addition, for children requiring complex outpatient dental procedures there is costs not only for the dentist, but also anesthesia as well as the risk associated with these procedures.

Early childhood caries can also turn into severe early childhood caries within a few months and can potentially progress to severe local and systemic infection which can be life threatening. For example, in 2007 the media reported that Demonte Driver a 12-year-old boy died of complications of an untreated dental abscess that spread to the brain causing an overwhelming infection [23]. 


\section{ECC Prevention}

Early childhood caries is a preventable condition through healthy nutrition, proper home dental care and early dental visits. However, since ECC is a multifactorial disease programs aimed at prevention become more complex in nature. There have been many interventions attempting to decrease the incidence of ECC.

\section{Fluoride}

Fluoride has a protective effect against the development of caries. Fluoride not only inhibits demineralization of the teeth, but also has been found to enhance remineralization of early caries lesions [7] [24]-[26]. Fluoride can occur naturally or by means of adding fluoride into a community's water supply. Fluoridation of water is consistently regarded as the most cost-effective method for caries prevention on a community level basis. For most United States communities, every dollar spent on community water fluoridation results in a savings of $\$ 38$ in costs to repair (fill) a decayed tooth [27].

The use of fluoride tooth paste is another source of fluoride for children and continues to be a common way to reduce caries for all children and most important for those children that may not benefit from community water fluoridation. Fluoride varnish also provides additional benefits for those high-risk children who may have limited access to fluoridated water. Fluoride varnish is proven to be easy to use as well as safe and effective for infants and toddlers [28].

\section{Oral Health Promotion in Primary Care}

Due to both the undersupply of dental providers and high rates of ECC there has been an increased professional and political interest in determining how dental education and care can be more easily accessed beyond the traditional dental offices for high-risk populations [9]. Plans to reduce caries in the pediatric population are beginning to include more creative interventions such as the use of oral assessment, oral health education and interventions as part of primary health care practices [6] [9] [29] [30] [31].

\section{Practicality of Oral Health Promotion}

Primary health care providers are in a key position to positively impact oral health and reduce ECC due to their frequent contacts with children and their families during the first few years of their lives. However, this unique opportunity to impact ECC may be prohibited by the health care provider's lack of willingness to take on oral health guidance and responsibilities [32]. Providers may feel that oral health promotion cannot possibly be included into an office visit due to time limitations. However, this does not have to be the case. Oral health promotion can be easily woven into the time frame of a well visit without requiring additional staff or time to perform the needed tasks.

It is important for all medical providers to consider the oral examination and education as part of the routine well child examination. Preventing oral health problems is the ultimate goal of focusing on oral health assessment and education during the multiple well child examinations in the first 2 years of life. However, identifying problems early on can also prevent further problems and allow for early referral to specialized dental services.

\section{Steps in Oral Health Promotion}

The following steps to delivering oral health services can be easily integrated into the well child care visit beginning with obtaining historical data. Socio-demographic data including socioeconomic status (SES) and community fluoridation should be clearly documented in the chart or asked by nursing personnel during the well child work-up. Family medical history should include dental health including dental diseases, dental care as well as having access to a dental provider. The child's past medical history should include any medical problems that may affect the development of the child's teeth as well as medication that may inhibit caries and dental development. A history of developmental problems can also alert practitioners to potential dental problems requiring specialized dental services. A family that is overwhelmed by a child with chronic medical conditions may rate oral care as a low priority and therefore have difficulty in performing basic oral health.

Dietary practices are known contributors to caries development. Nutritional intake related to oral health can be determined by asking questions including: type and frequency of meals; type and frequency of snacks and drinks; use of a bottle or cup and whether or not the infant sleeps with their bottle or breast feeds on demand. 
Parental knowledge about proper oral health care and the importance of the child's primary teeth are factors known to improve a child's oral health outcomes. Feeding habits provide a basis for determining current parental knowledge as well as their perceived susceptibility of poor oral health outcomes for their child. Parents can benefit from the education provided on the risks of children's intake of sugary fluids and snacks and information on alternatives choices for their young children who continue to require frequent feedings and fluid intake throughout the day.

During the time the provider is examining the child's mouth is the time to observe for any white spots, discoloration or decay, presence of plaque, friability of the gums and saliva production which indicate poor oral health and need for dental referral [33]. During this section of the child's exam the provider can ask about whether the parents' are brushing their child's teeth, the frequency of brushing, the use of a toothbrush and toothpaste. Demonstrating tooth brushing with a new brush provided to the infant and child is ideal for reinforcing the importance of oral care [33].

Providing a helpful handout for oral health is one way to support the oral health guidance provided during the well child visit (Figure 1).

Application of fluoride varnish has been proven to be an effective method of reducing ECC by assisting in protecting primary teeth as well as re-mineralizing teeth that have begun to experience early decay. The fluoride application process is easy to perform and can be applied as early as 6 months of age or when the first tooth as erupted. The practitioner or a trained staff member can apply the varnish at the completion of the visit at the same time the child's recommended immunizations are being administered.

The preferred position for fluoride application in the infant is the knee to knee position (Figure 2) and for the older child position on the exam table and work from above the head of the table.

Applying the varnish includes the following steps: drying the teeth with gauze and apply varnish to all surfaces of the teeth. Advise the parents to provide their child with a soft diet the remainder of the day as well as to hold off brushing their child's teeth until the next morning. Most companies that supply fluoride varnish will also provide a tear off sheet with directions for after care. Providing the child with a toothbrush at this time is ideal for further reinforcement of the importance of oral health as it relates to overall health and to help the child buy into oral health with a colorful brush to take home.

\section{Practice Benefits}

Including a new task into an already busy clinical practice takes time and planning, as well as a financial investment to develop and sustain these activities. Therefore, the thought of delivering oral health services during the well-child visit may seem unreasonable from a financial standpoint. However, in order to increase access to

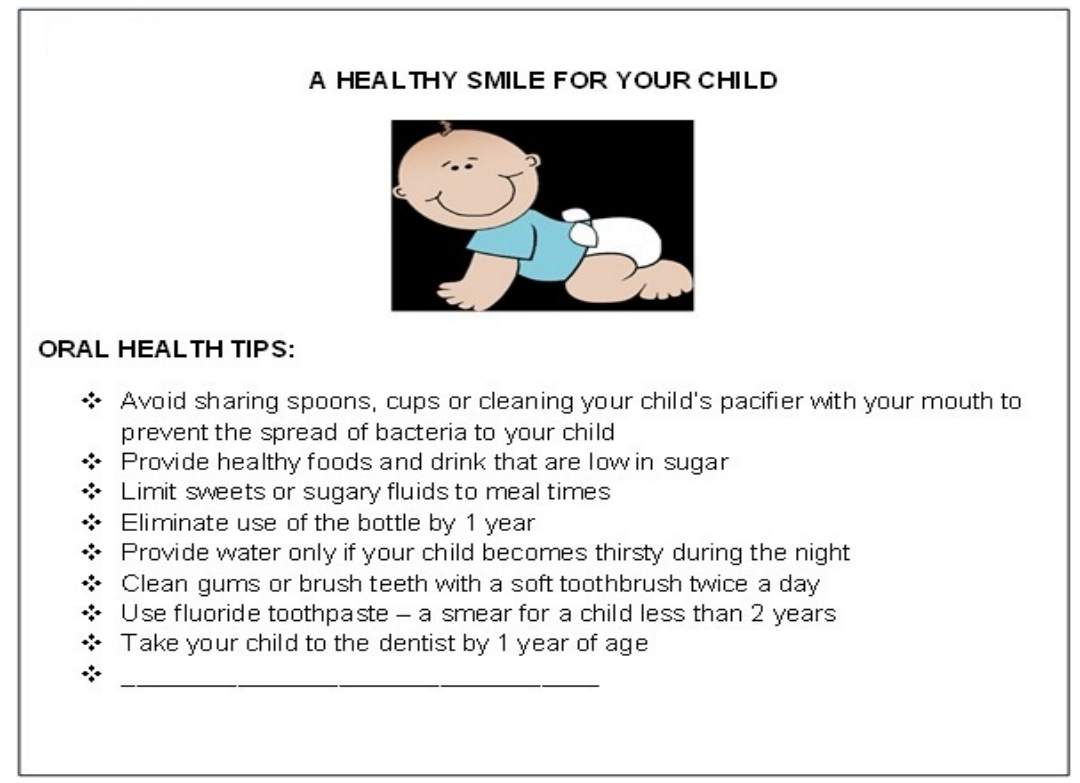

Figure 1. Oral health tips. 


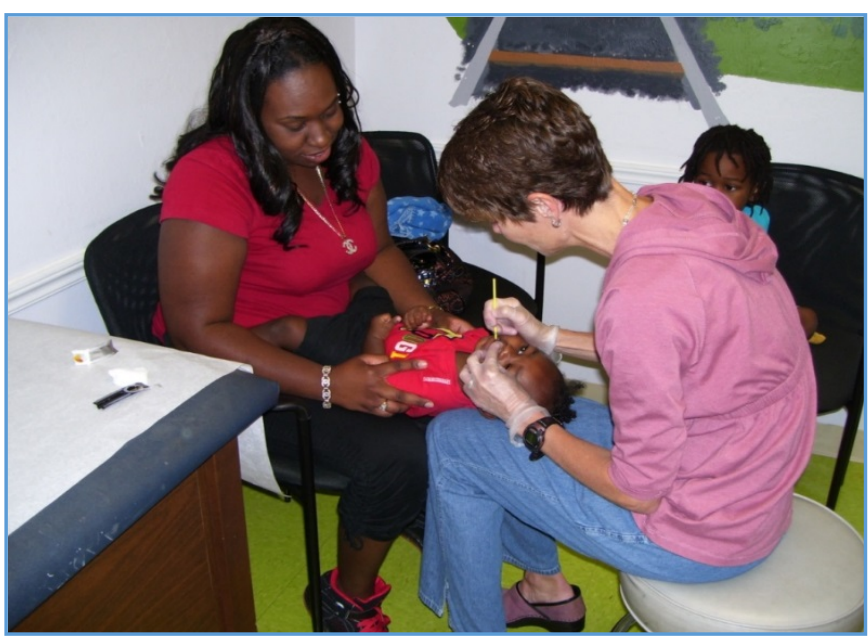

Figure 2. Knee to knee position for fluoride varnish application.

preventive dental care for young children many states have instituted reimbursement to primary care provider for providing certain oral health services that can be completed in their offices. Currently 34 states reimburse primary care providers for preforming preventive oral health services on children who receive Medicaid services [34]. These services include oral risk assessment, examination/screening, fluoride varnish application and anticipatory guidance. Each state may have slightly differences service restrictions and reimbursement rates. Many states limit the number of fluoride varnish application to 3-4 annually with reimbursement rates for fluoride varnish application ranging from $\$ 10.00$ to over $\$ 50.00$ [34].

\section{Conclusions}

Childhood caries is a preventable disease. However, the rate of dental disease and poor outcomes for children continues to climb. The lack of dental providers, which is a substantial barrier to care, is likely to remain unchanged. Therefore, creative preventive programs such as the utilization of primary care practitioners to provide basic oral assessment, care and teaching should be encouraged and endorsed by the community and government by continuing to appropriately reimburse health providers for oral health services. Providers can also learn to identify children at risk for dental disease and refer them to willing and appropriate dentists for follow-up care. Healthcare Administrators can play a major role by providing practice owners and providers with a detailed business plan, highlighting the profit and losses, as well as assisting with the layout of the workflow, inventory management and medical staff utilization.

Pediatric primary care providers are trusted by parents to care for their children and have an ideal opportunity to make a lasting impression and create behavioral changes in oral health during their frequent contacts with children and families. Additionally, including oral health care during the well child care visits allows the child to experience some of the benefits of fluoride without needing any further efforts from the parents. Emphasizing the importance of improving the oral health of children which affects their overall health has been a main focus in bringing medical and dental communities together to accomplish this goal. The benefits of early preventive services are repeatedly recognized in the literature as more and more states and providers are now willing to take on this role.

In order to maximize the number of primary care providers who integrate oral health promotion into their practice there needs to be further support by both professional and governmental agencies. Included should be the provision of educational opportunities for primary care providers, which includes adopting oral health clinical competencies. Additionally, there should be responsiveness from the government to address the cost of implementation of oral health programs and to provide appropriate incentives to the practice and practitioners. As more primary care providers become active in oral health promotion in their practice there can be further growth in the publics' awareness of the importance of oral health as it related to overall health. Over time this can eventually help in the reduction in dental disease and ultimately reduce the cost for future dental restoration and dental diseases. 


\section{References}

[1] US Department of Health and Human Services (2000) Oral Health in America: A Report of the Surgeon General. Department of Health and Human Services, National Institute of Dental and Craniofacial Research, National Institutes of Health. http://www.surgeongeneral.gov/library/reports/oralhealth/index.html

[2] Beltran-Aguilar, E.D., Barker, L.K., Canto, M.T., Dye, B., Gooch, B., Griffin, S., Wu, T., et al. (2005) Surveillance for Dental Caries, Dental Sealants, Retention, Edentulism, and Enamel Fluorosis United States, 1998-1994 and 1999-2002. MMWR Surveillance Summer 2005, 54, 1-44. www.cdc.gov/mmwr/PDF/ss/ss5403.pdf

[3] Center for Disease Control and Prevention [CDC] (2010) National Center for Health Statistics, Oral and Dental Health. http://www.cdc.gov/nchs/fastats/dental.htm

[4] Douglass, J., Douglass, A. and Silk, H. (2004) A Practical Guide to Infant Oral Health. American Family Physician, 70, 2113-2120. www.aafp.org/afp/2004/1201/p2113.html

[5] Gussy, M., Waters, E., Walsh, O. and Kilpatrick, N. (2006) Early Childhood Caries: Current Evidence of Aetiology and Prevention. Journal of Pediatric and Child Health, 42, 37-43. http://dx.doi.org/10.1111/j.1834-7819.2007.00010.x

[6] Krol, D. (2003) Dental Caries, Oral Health and the Pediatrician. Current Problems in Pediatric and Adolescent Health care, 33, 253-270. http://dx.doi.org/10.1016/S1538-5442(03)00093-2

[7] Selwitz, R., Ismail, A. and Pitts, N. (2007) Dental Caries. The Lancet, 369, 51-59. http://dx.doi.org/10.1016/S0140-6736(07)60031-2

[8] Yost, J. and Li, Y. (2008) Promoting Oral Health from Birth through Childhood: Prevention of Early Childhood Caries. American Journal of Maternal Child Nursing, 33, 17-23. http://dx.doi.org/10.1097/01.NMC.0000305652.01743.8d

[9] American Academy of Pediatrics Policy Statement (2003) Oral Health Risk Assessment Timing and Establishment of the Dental Home. Pediatrics, 11, 1113-1116. http://pediatrics.aappublications.org/content/111/5/1113.full

[10] Crall, J. (2006) Access to Oral Health Care: Professional and Societal Considerations. Journal of Dental Education, 20, 1133-1138. www.jdentaled.org/content/70/11/1133.full

[11] Edelstein, B.L. (2002) Disparities in Oral Health and Access to Care: Findings of National Surveys. Ambulatory Pediatrics, 2, 141-147. http://dx.doi.org/10.1367/1539-4409(2002)002<0141:DIOHAA >2.0.CO;2

[12] Kenney, G., Ko, G. and Ormond, B. (2000) Gaps in Prevention and Treatment: Dental Care for Low Income Children. National Survey of American's Families, Series B. No. B1-15, The Urban Institute, Washington DC. http://dx.doi.org/10.2105/AJPH.2004.056523

[13] Kenney, G., McFeeters, J. and Yee, J. (2005) Preventive Dental Care and Unmet Dental Needs among Low-Income Children. American Journal of Public Health, 95, 1360-1366. http://dx.doi.org/10.2105/AJPH.2004.056523

[14] Seale, N. and Casamassimo, P. (2003) Access to Dental Care for Children in the United States: A Survey of General Practitioners. Journal of the American Dental Association, 138, 1630-1640.

http://www.ncbi.nlm.nih.gov/pubmed/14719761 http://dx.doi.org/10.14219/jada.archive.2003.0110

[15] Pew Center on the States (2011), The State of Children's Dental Health: Making Coverage Matter. Washington DC. http://www.pewstates.org/research/reports/the-state-of-childrens-dental-health-85899372955

[16] American Academy of Pediatric Dentistry (2011) Policy on Early Childhood Caries (ECC): Unique Challenges and Treatment Options. American Academy of Pediatric Dentistry, Council on Clinical Affairs. http://www.aapd.org/media/Policies Guidelines/P ECCUniqueChallenges.pdf

[17] Li, Y. and Wang, W. (2002) Predicting Caries in Permanent Teeth from Caries in Primary Teeth: An Eight Year Cohort Study. Journal of Dental Research, 81, 561-566. http://dx.doi.org/10.1177/154405910208100812

[18] Kuo, L., Polson, A. and Kang, T. (2008) Association between Periodontal Diseases and Systemic Diseases: A Review of the Inter-Relationships and Interactions with Diabetes, Respiratory Disease, Cardiovascular Diseases and Osteoporosis. Public Health, 122, 417-433. http://dx.doi.org/10.1016/j.puhe.2007.07.004

[19] The National Institute of Dental and Craniofacial Research (2002) A Plan to Eliminate Craniofacial, Oral, and Dental Health Disparities, 1-25.

http://www.nidcr.nih.gov/NR/rdonlyres/932B8B7D-E114-4491-BE85-ABA6F29663AE/0/hdplan.pdf

[20] Savage, M., Lee, J., Kotch, J. and Vann, W. (2004) Early Preventative Dental Visits: Effect on Subsequent Utilization and Costs. Pediatrics, 114, 418-423. http://dx.doi.org/10.1542/peds.2003-0469-F

[21] Truman, B., Gooch, B. and Sulemana, I., et al. (2002) Task Force on Community Preventive Services. Reviews of Evidence on Intervention to Prevent Dental Caries, Oral and Pharyngeal Cancers and Sports Related Craniofacial Injuries. American Journal of Preventative Medicine, 23, 21-54.

http://www.thecommunityguide.org/oral/oral-ajpm-ev-rev.pdf 
http://dx.doi.org/10.1016/S0749-3797(02)00449-X

[22] Kanellis, M., Damnano, P. and Momany, E. (2000) Medicaid Costs Associated with the Hospitalization of Young Children for Restorative Dental Treatment under General Anesthesia. Journal of Public Heath Dentistry. 60, 28-32. http://dx.doi.org/10.1002/bdra.20726

[23] Otto, M. (2007) For Want of a Dentist. Washington Post, Washington DC. http://www.washingtonpost.com/wp-dyn/content/article/2007/02/27/AR2007022702116.html

[24] Featherstone, J. (1999) Prevention and Reversal of Dental Caries: Role of Low Level Fluoride. Community Dentistry and Oral Epidemiology, 27, 31-40.

[25] Jones, J. (2008) Optimal Caries Prevention: Evidence Based Recommendations for Use of Fluoride Varnish. Oral Health Journal, 1-7.

http://www.oralhealthgroup.com/news/optimal-caries-prevention-evidence-based-recommendations-for-use-of-fluoride -varnish/1000219906/?\&er=NA

[26] Kaminsky, L., Mahoney, M., Leach, J., Melius, J. and Miller, M. (1990) Fluoride: Benefits and Risks of Exposure. Oral Biology and Medicine, 1, 261-281.

[27] American Dental Association (2005) Fluoridation Facts. http://www.ada.org/sections/professionalResources/pdfs/fluoridation-facts.pdf

[28] Milgrom, P., Zero, D. and Tanzer, J. (2009) An Examination of the Advances in Science and Technology of Prevention of Tooth Decay in Young Children since the Surgeon General's Report on Oral Health. Academic Pediatrics, 9, 404409. http://dx.doi.org/10.1016/j.acap.2009.09.001

[29] dela Cruz, G., Rozier, R. and Slade, G. (2004) Dental Screening and Referral of Young Children by Pediatric Primary Care Providers. Pediatrics, 114, 642-652. http://dx.doi.org/10.1542/peds.2004-1269

[30] Nowak, A. and Casamassimo, P. (2002) The Dental Home: A Primary Care Oral Health Concept. Journal American Dental Association, 133, 93-98. www.ncbi.nlm.nih.gov/pubmed/11811749 http://dx.doi.org/10.14219/jada.archive.2002.0027

[31] Rozier, R., Sutton, B., Bawden, J., Haupt, K., Slade, G. and King, R. (2003) Prevention of Early Childhood Caries in North Carolina Medical Practices: Implications for Research and Practice. Journal of Dental Education, 67, 876-885. http://www.jdentaled.org/content/67/8/876.full.pdf

[32] Krol, D. (2004) Educating Pediatricians on Children's Oral Health: Past Present and Future. Pediatrics, 113, 487-492. http://dx.doi.org/10.1542/peds.113.5.e487

[33] Mattheus, D. (2013) Efficacy of Oral Health Promotion in Early Childhood. (Order No. 3572481, University of Hawaii at Manoa) ProQuest Dissertations and Theses, 113. http://search.proquest.com/docview/1430304127?accountid $=10920$

[34] Cantrell, C. (2009) Engaging Primary Care Medical Providers in Children's Oral Health. (Portland, ME: National Academy for State Health Policy, September 2009) http://iohwa.org/2006/EngagingPrimaryCareProvidersChildOralHealth.pdf 